\title{
An Information System Platform for Water Resources Operation in Shiyanghe River Basin, China
}

\author{
Siyu Cai, Xiaohui Lei, Weihong Liao, Yang Yu, Lang Yu \\ Department of Hydraulic Engineering Tsinghua University Beijing, 100084, China \\ China Institute of Water Resources and Hydropower Research Beijing, 100038, China
}

\begin{abstract}
Currently, more and more arid and semi-arid areas in Northwestern China are facing with severe water problems. The Shiyanghe River basin is in the east of Hexi Corridor in Gansu Province with little rainfall and fragile ecological environment. As water pollution and water waste exist with water shortage, a serious conflict of water supply and demand is arising, accompanied with a series of water ecological problem. Thus, we must take measures to ensure the water resources to be used properly for long-term sustainable development. Water resources operation is taken reasonably which can achieve the overall regulation of basin water resources and which is an important method to achieve sustainable development. Taking the Shiyanghe River Basin as the research object, based on the basin data, this paper built the runoff forecasting model, water demand prediction model, water resources operation model and groundwater simulation model. Therefore, an information system platform for water resources operation in Shiyanghe River Basin is built based on GIS with an integrated data and computational models.
\end{abstract}

\section{INTRODUCTION}

With the rapid development of global economy and population, water usage is increasing continuously, and water shortage has become the primary contradiction of water resources. However, the current development and utilization of water resources is increasingly affected by human activities, so a lot of conflicts have occurred in the time-spatial distribution of water resources and the demand for industrial and ecological water. All of these have greatly constrained the sustainable development of economy, society and ecological environment [1]. Water resources operation is the best way to solve this problem [2]. Through the combination of runoff forecasting and demand prediction, regulating water in the area of a basin, can make the maximum usage of existing water resources and solve the contradiction between uneven distribution and huge demand of water resources.

Shiyanghe River Basin is deep in the continental hinterland, with a continental temperate arid climate, strong solar radiation, sufficient sunshine, large temperature difference, less precipitation, strong evaporation and dry air. Shiyanghe River Basin is a typical water-deficit area, whose per capita availiablity of water resources is only $744 \mathrm{~m}^{3}$, which is well below the international standard of $1000 \mathrm{~m}^{3}$. In the last 20 years, with the development of social and economic development of the basin, the contradiction between water resources supply and demand has been very sharp. Although the current degree of water resources exploitation reaches $172 \%$, the basin still has a big water shortage of 543 million $\mathrm{m}^{3}$. Due to the unreasonable structure of water usage, agricultural irrigation has been the major water in Shiyanghe River Basin for a long time (the proportion of irrigation water is up to $86 \%$ ). However, The GDP of per cubic meter water in the whole basin is only $4.81 \mathrm{RMB}$, which is about $1 / 5$ of the national average level, and the efficiency of water resources utilization is very low. Besides, with the rapid economic development and increasing trend of urbanization, the city's sewage water emission is significantly rising in the middle reaches of the basin, and water quality deterioration has aggravated the downstream water crisis and serious ecological problems. In addition, the local weak management has caused a disordered utilization of water resources and decreasing underground water level, and furthermore, deteriorated water and ecological environment.

However, the current water resources operation systems are mainly studied by developed countries and are suitable for water resources abundant areas. For example, due to the abundant water resources in Canada, irrigation infiltration, river channel loss and reservoir leakage loss are not involved in the WRMM model (Water Resource Management Model) [3], as well as the interconversion between surface water and groundwater and groundwater usage. However, China suffers from acute water shortage, especially in arid and semi-arid regions. Water problems involve water usage contradiction, fragile ecological environment, huge water consumption, serious groundwater exploitation, poor information management of water resources and so on.

Based on the above background, it is necessary to build an information system platform for water resources

\footnotetext{
*Corresponding author: caisy16@mails.tsinghua.edu.cn
} 
operation in Shiyanghe River Basin to realize the unified management and regulation. The platform includes a complete set of database management system and relevant bundled software system. The monitored data transfers to the database in the dispatching center, assisted by bundled softwares, can realize information sharing and provide data for statistical analysis, thereby forming a complete information system platform. The functions of the platform include runoff forecasting, water demand prediction, water resources operation and groundwater simulation. Besides, the platform adopts modular programming ideas to separate models and data. The separate management of different modules and separate computation of parameters can realize the structuring and expandability of models.

The development of the information system platform can effectively simplify business process among different departments, realize online information publish and water resources reasonable allocation. On the basis of dynamic monitoring and accurate forecasting, the unified management and regulation of water resources can provide strong decision-making support and management tools for basin water resources scientific and unified planning and dynamic management for water administration department.

\section{Water Resources Operation Model}

\subsection{Water Resources Optimal Operation Model (WROOM)}

WROOM [4-6] is a water resources system model combining optimization and simulation technology, which can not only describe the real water system but can also achieve optimal goals. This study divided the whole operation period into multiple sub-periods, and each subperiod is composed of one or several operation intervals. Fig.1 shows the relationship between simulation and optimization. For each sub-period, firstly, determine the operation strategy (such as water supply structure and priority) according to the stage information (such as reservoir storage capacity and exploitable quantity of groundwater) from the previous period through "simulation model"; then build the "optimal model" for the current sub-period according to these strategies. After solving the model, we can get the supply and demand balance information and stage information so as to provide data for the next operation period.

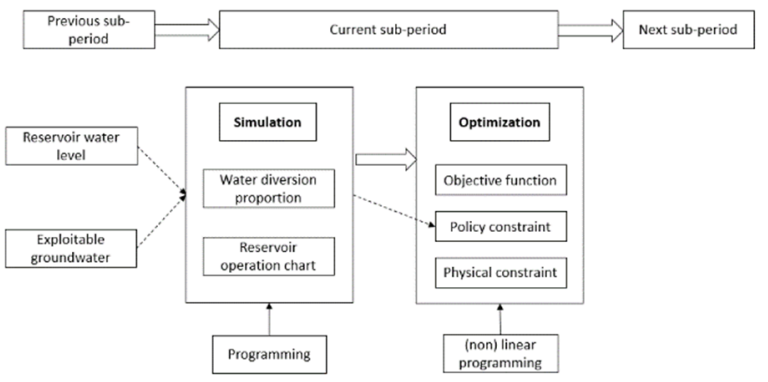

Figure 1. The concept map about the coupling method of simulation and optimization in WROOM model
The basic theory of WROOM model is water balance [7-9] which can be classified into three types: reservoir water balance, node water balance and compute unit water balance (Fig.2). Compared with the regular water resources operation model, WROOM adds some constraints for describing operation rules so as to simulate water system operation mode better. Besides, WROOM model can define optimal period and constraint rules according to users' requirements, which increases the applicability of the model. The objective functions of WROOM model include maximum water supply, minimum water deficit and minimum abandoned water.

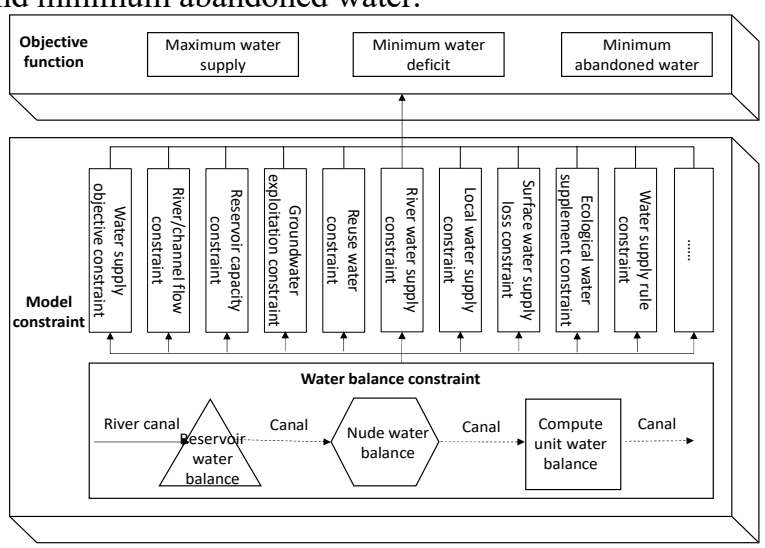

Figure 2.

Structure of WROOM model

\subsection{Detailed Definition of WROOM Model}

\section{1) Model Paremeters}

Model parameter defines all input data required by WROOM, including: a) inflow parameters of reservoir, node and compute unit; b) reservoir storage, evaporation and leakage parameters; c) water demand parameters for different compute units and industries; d) water deficit ratio weight of different industries; e) channel water flow parameter; f) groundwater utilization parameter; g) sewage treatment and reuse parameter; h) irrigation regression parameters of compute unit; i) local runoff direct utilization parameter.

\section{2) Decision Variables}

Model decision variables define variables that need to be solved optimally, including: a) decision variables about reservoir; b) decision variables about surface water channel, transferring water channel and water recession channel; c) decision variables about node; d) decision variables about compute unit.

\section{3) Constraint Equations}

Model constraint defines all kinds of constraints in water resources regulation problems, involving project constraint, policy constraint, preference constraint and so on. During the long-term practice of water resources demand and supply balance simulation, a complete theory framework of water resources system has been formed. Specifically, model constraints can be divided into three types: a) reservoir constraint [10-11]; b) node constraint [12]; c) compute unit constraint.

Reservoir water balance: 


$$
\begin{aligned}
W_{\text {interzone inflow }} & +W_{\text {upstream inflow }} \\
& =W_{\text {abandoned water }}+W_{\text {water supply }} \\
& +S_{\text {loss }}
\end{aligned}
$$

Node water balance:

$$
\begin{aligned}
W_{\text {interzone inflow }} & +W_{\text {upstream inflow }} \\
& =W_{\text {abandoned water }}+W_{\text {water supply }}
\end{aligned}
$$

Compute unit water balance:

$$
\begin{aligned}
& W_{\text {local runoff }}+W_{\text {unit reuse water }} \\
& =W_{\text {local direct use }}+W_{\text {water supply }} \\
& +W_{\text {abandoned water }}
\end{aligned}
$$

\subsection{Water Resources Operation Model Construction in Shiyanghe River Basin}

\section{1) Water Resources System Conceptualization}

WROOM model combines point, line and plane to conceptualize water resources system into five basic elements: reservoir, underground reservoir, node, river network and compute unit. By building the upstreamdownstream relation, water supply relation and water recession relation among these elements, the whole water resources system can be conceptualized as Fig.3.

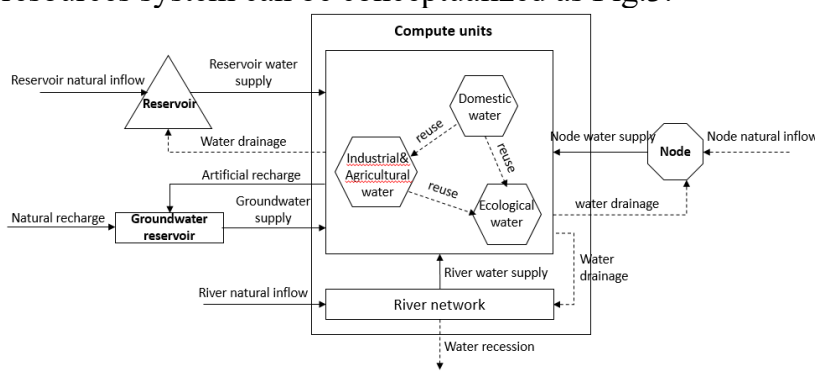

Figure 3.

Concept map of water resources system conceptualization

From the perspective of water sources, the water resources system of Shiyanghe River Basin refers to various water sources such as surface reservoirs, underground aquifers, external transferring water and reuse water, etc. From the point of view of water users, there are many kinds of users, including domestic, industry, agriculture and ecology. In terms of water supply relationship, it is not only need to consider water supply of surface water, groundwater and transferring water, but also need to consider water recession and reuse. According to the water supply rules, water supply should be carried out in accordance with the priority of water sources and users.

Through the analysis of Shiyanghe River Basin water resources network, combined with the modeling approach of WROOM model, this study chose several surface reservoirs such as Xidahe, Huangcheng, Jinchuanxia, Xiyin, Nanyin, Zamu, Huangyang, Gulang and Hongyashan, water transfer projects, groundwater and irrigation areas to conceptualize water resources system of Shiyanghe River Basin. Meanwhile, the flow of Caiqi section was chosen as the controlling goal. In conclusion, the whole basin is divided into 9 reservoirs, 16 irrigation areas (compute units), one control node (Caiqi section), 12 surface water supply channels, 16 groundwater supply channels, 3 water diversion channels and 16 water recession channels.

\section{2) Model Construction and Solution}

Water resources operation model in Shiyanghe River Basin is built by MSF, then transferred into C language and inserted into the platform through VS. Model computation needs to read database, including description information about water resources network diagram, long series inflow, water demand information, operation rules, engineering information, etc. The computation results will be stored in the Oracle database, which can be directly called and displayed on the system platform.

When using MSF to solve large-scale equations, MSF can automatically determine the optimal solver, such as CPLEX, Gurobi, LINDO, lp solve, Ziena, Mosek and so on.

\section{Information SYSTEM PLATFORM}

\subsection{Structure of Platform}

The information system platform for water resources operation in Shiyanghe River Basin is a GIS-based water resources management decision support system developed with C\# language, MSF and GAMS modeling tools based on model base and database. The system is developed by the method of modularization, through the separation and coupling of modules, it can serves for water resources operation in Shiyanghe River Basin. The platform is a complicated system integrated with data and models, where the database is built and managed by Oracle $10 \mathrm{~g}$, mainly including social and economic information, hydrometeorological information, water resources developing and utilization information, hydrogeological data, groundwater data, operation schemes and so on. Meanwhile, the model base is composed of runoff forecasting model, water demand prediction model, water resources operation model and groundwater simulation model. The database provides data-support for the model base, while the model base offers updated operation schemes for the database.

The runoff forecasting model can forecast reservoir available water supply with consideration of the current reservoir storage capacity. Water demand prediction model can predict agricultural, industrial, domestic and ecological water demand. The groundwater simulation model is used to simulate groundwater spatial and temporal dynamics. Water resources operation model uses information such as water diversion ratio, incoming water and water demand to design operation schemes based on reasonable water allocation. The general structure of the information system platform for water resources operation in Shiyanghe River Basin is shown in Fig. 4. 


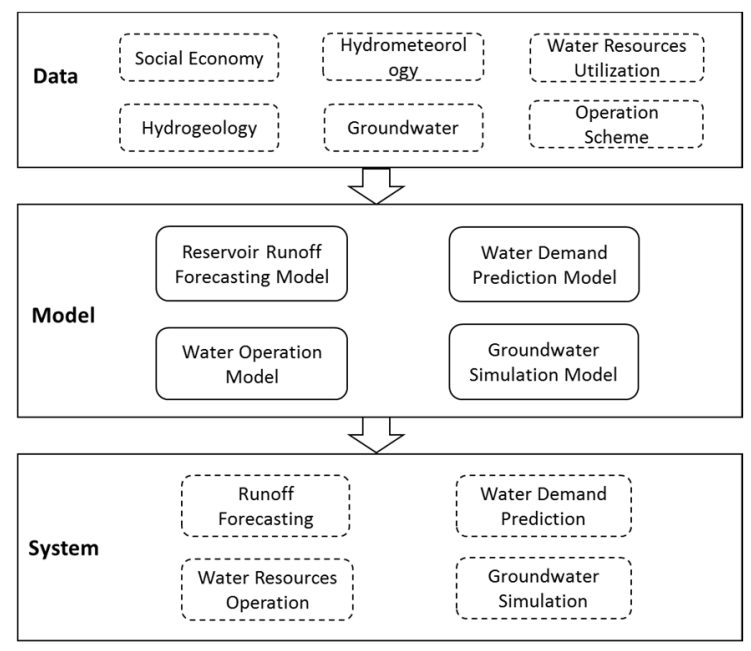

Figure 4. Structure of platform

\subsection{Functions of Platform}

\section{1) Runoff Forecasting}

The common runoff forecasting method generally adopts rainfall-runoff model. However, considering the few rainfall in arid and semi-arid regions, some runoff comes from melting snow and the changing process is relatively stable. Consequently, this platform built statistic models based on historical data and chose BP Neural Network [13-16] and Autoregressive Model [17] to forecast runoff. This method is easier and more practical than traditional basin hydrological models as it doesn't need detailed topographical and hydrological data and can achieve good results in basin whose runoff change is relatively stable.

\section{2) Water Demand Prediction}

According to "National Water Resources Planning", water demand prediction involves two parts: national economic water demand and ecological environmental water demand. Where the national economic water demand can be further divided into domestic water, agricultural water and industrial water.

\section{3) Water Resources Operation}

This platform adopts WROOM model to allocate and regulate water resources in Shiyanghe River Basin. The input data mainly include: a) monthly inflow process of reservoirs and nodes during the regulation period; b) water storage condition of reservoirs at the beginning of regulation period. The output data mainly include: a) supply and demand balance of administrative regions and irrigation areas; b) water storage and discharge process of reservoirs; c) underground water exploitation process of compute units.

\section{4) Groundwater Simulation}

The main function of groundwater simulation model is forecasting spatial and temporal dynamic changes of groundwater level according to basin geological conditions and monitoring data, combined with groundwater recharge forecasting results and exploitation amount. In order to realize numerical simulation and integration with the platform, the groundwater simulation model was built on the basis of MODFLOW [18-21] developed by USGS. Coupled with GIS and basic database, the groundwater numerical simulation system was successfully constructed.

\section{Results}

The following pictures show some functional interferes of the information system platform for water resources operation in Shiyanghe River Basin. Fig.5(a) is the runoff forecasting interface, which is composed of long-series data management, forecasting model choice, forecasting calculation and inflow process. Fig.5(b) is water demand prediction interface, which can predict water demand in irrigation area and administrative area through setting water demand prediction data and calling water demand prediction model. Fig.5(c) is the groundwater simulation interface, composed of model parameter mode and simulation results mode, it can also demonstrate water level changing process of groundwater aquifer dynamically. Fig.5(d) is the water resources operation interface, consisting of consists of regulation parameter, regulation plan and water balance result. Based on inflow forecasting and water demand prediction results in 2013, the study uses water resources regulation model to simulate regulation results. The water transfer plan of 2013 is shown in Table I.

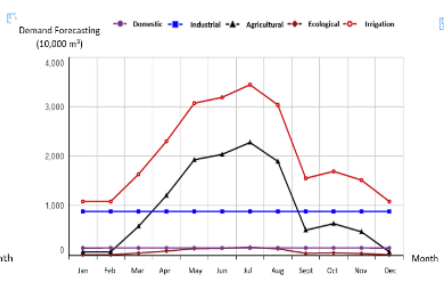

(b) 


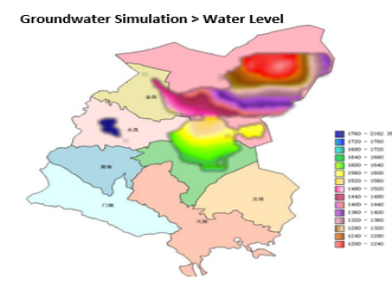

(c)

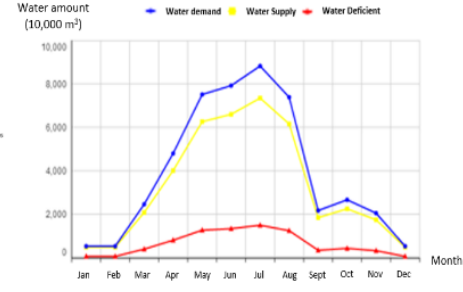

(d)

Figure 5. Functional interfaces of the platform

TABLE I. THE RESULTS OF THE SHIYANGHE RIVER BASIN WATER TRANSFER PLAN IN 2013

\begin{tabular}{|c|c|c|c|c|}
\hline $\begin{array}{c}\text { Tranf } \\
\text { errin } \\
\text { g } \\
\text { water }\end{array}$ & $\begin{array}{c}\text { Water } \\
\text { recession } \\
\text { in } \\
\text { irrigation } \\
\text { districts }\end{array}$ & $\begin{array}{c}\text { Transfer } \\
\text { ring } \\
\text { water } \\
\text { from } \\
\text { reservoir }\end{array}$ & $\begin{array}{c}\text { Total } \\
\text { amount of } \\
\text { transferrin } \\
\text { g water }\end{array}$ & $\begin{array}{c}\text { Transfer } \\
\text { ring } \\
\text { water in } \\
\text { Caiqi } \\
\text { section }\end{array}$ \\
\hline $\begin{array}{c}6100 . \\
3\end{array}$ & 3808.92 & 19654 & 29563.26 & 25000 \\
\hline
\end{tabular}

\section{Conclusions}

The information system platform for water resources operation in Shiyanghe River Basin adopts advanced water resources operation technologies and computer aided decision, raises the information management level in Shiyanghe River Basin, which is significant for the development of basin water resources operation. The opensource GIS-based system platform provides a friendly GISbased modeling environment to carry out basin runoff forecasting, water demand prediction, basin water resources regulation and groundwater simulation. The application in the Shiyanghe River Basin also shows the capability of user-friendliness and providing information for decision makers so as to guide practices. However, considering the complexity and uncertainty of water resources operation, effort should be expended to improve forecasting accuracy and make the software system more efficient for practical water resources management.

\section{ACKNOWLEDGEMENT}

This research was financially supported by Intergovernmental Key International S\&T Innovation Cooperation Program (No.2016YFE0102400)

\section{REFERENCES}

1. Xiaohui L, Hao W, Yunzhong J. Complex Water Resources System Simulation and Optimization [M]. Beijing: China Water\&Power Press, 2012.

2. Kun D, Xuan Z, Yongsheng Y. Overview of Basin Water Resources Regulation Research [J]. Journal of Economics of Water Resources, 2011, 29(6):23-27.

3. Alan, Alberta Environment Natural Resources Service Bow Region Water Administration Branch. Water resources management model computer program description [R]. Canada, 1999.
4. Haichen L, Xuechun W, Xiaohui L, Xiaochun L, Yamei W. WROOM Model and its Application of Water Operation in Wei River Basin[J]. South-toNorth Water Transfers and Water Science \& Technology, 2014, (02):29-33.

5. Xiaohui L, Xu W, Yunzhong J, Junxie Y. Water resources optimal operation Model WROOM I. Theory[J]. Journal of Hydraulic Engineering, 2012,(03):282-288.

6. Xiaohui L, Xu W, Yunzhong J, Hao W. Water resources optimal operation Model WROOM II. Application[J]. Journal of Hydraulic Engineering, 2012, (02):225-231.

7. Under O I, Mays L W. Model for real-time optimal flood control operation of a reservoir system [J]. Water Resources Management, 1990,(4):24-45.

8. Peijun S, Dongguo S. Inter-basin water diversion project optimization planning hybrid simulation model research [J]. Journal of Systems Engineering, 1992, 7(2):43-52.

9. LITTLE J D C. The use of storage water in a hydroelectric system [J]. Operational Research, 1995,(3):187-197.

10. AHMED I. On the determination of multi reservoir operation policy under uncertainty [D]. Arizona: The University of Arizona, 2001.

11. Zhiguo C, Guangqian W, Jiahua W. Self-tuning control model for the Yellow River water regulation system [J]. Tsinghua Univ.(Sci\&Tech), 2004,44(12):1660-1663.

12. $\mathrm{Yu} \mathrm{W}$, Libin $\mathrm{Y}$, Chuanhe $\mathrm{H}$, et al. using the object oriented program to research and develop the water dispatching decision support system [J]. Advances in Water Science, 2000, 11(4):441-446.

13. Shuang C. Application of neural network, fuzzy system in motion control [M]. Hefei: Press of USCT, 2001:1-31.

14. Statsoft . Statistica Neural Networks [M] . Manual Tulsa: Statsoft, Inc. , 1999.

15. Anderson J A. An Introduction to Neural Networks [M] . London: MIT Press, 1995.

16. Bishop C M . Neural Netwoks for Pattern Recognition [M] . Oxford: Clarendon Press, 1995.

17. Jing D, Quanshou L. Stochastic hydrology [M]. Beijing: China Water \& Power Press, 1997. 
18. Michael M G, Harbaugh A W. A modular threedimensional finite-difference ground-water flow model [M]. Washington: United States Government Printing Office, 1988.

19. Linhong W, Longcang Shu, Zhenchun H. The present situation and development tendency of groundwater flow numerical simulation [J]. Journal of Chongqing University: Natural Science Edition, 2000, 23(Sup.1): 50-52. (In Chinese)

20. Perkins S P, Sophocleous M. Development of a comprehensive watershed model applied to study stream yield under drought conditions [J]. Ground Water, 1998, 37(3): 418-426.

21. Yuanyuan S, Yunzhong J, Xiaohui L, et al. Current practice and development trend in numerical modeling of groundwater in China $[\mathrm{J}]$. Journal of China Institute of Water Resources and Hydropower Research, 2009, 7(1):57-61. 